\title{
A Methodological Nexus of Pierre Bourdieu and Kathy Charmaz: An Example from a Doctoral Study
}

\author{
Virgininia Dube-Mawerewere \\ University of Zimbabwe, College of Health Sciences, Harare, Zimbabwe \\ Email: virgydube@gmail.com
}

How to cite this paper: Dube-Mawerewere, V. (2017). A Methodological Nexus of Pierre Bourdieu and Kathy Charmaz: An Example from a Doctoral Study. Advances in Applied Sociology, 7, 261-269.

https://doi.org/10.4236/aasoci.2017.77016

Received: May 31, 2017

Accepted: July 21, 2017

Published: July 24, 2017

Copyright $\odot 2017$ by author and Scientific Research Publishing Inc. This work is licensed under the Creative Commons Attribution International License (CC BY 4.0).

http://creativecommons.org/licenses/by/4.0/ (c) (i) Open Access

\begin{abstract}
This article discusses the example of how Pierre Bourdieu and Kathy Charmaz's concepts were applied in a doctoral research study. Bourdieu's concepts have been proved to be useful in comprehending functionality within social groups. Charmaz's notion of constructivism on the other hand emphasises the need to engage participants in constructing their reality from an epistemological perspective. Thirty two participants in this article were an equivalent of a social group. The study included three main participant systems of care: the medical/health, the judiciary and the prison systems. This discussion highlights how Bourdieu illuminated the exploration of mental health service functional inequalities within these systems in Zimbabwe.
\end{abstract}

\section{Keywords}

Pierre Bourdieu, Kathy Charmaz, Medical, Framework, Health, Judiciary, Prison

\section{Introduction}

The purpose of the research study under discussion was to develop a medicojudicial framework for the rehabilitation of forensic psychiatric patients in Zimbabwe, Africa. The study used the grounded theory approach utilising a mixed sequential dominant status design (QUAL/quant). The discussion will focus on the qualitative aspect of the study. In the study, the researcher's priority metatheoretical approach was constructivism according to the Charmaz. Purposive sampling of key stakeholders was the primary method and theoretical sampling became necessary as the study evolved in the qualitative phase.

The theoretical framework that was used as a point of departure for the study 
was conceptualised by Pierre Bourdieu, a French philosopher. The reality of participants in the study was illuminated by utilisation of Pierre Bourdieu's perspective (Grenfell, 2004). These concepts included habitus, field and capital. Encapsulated within these Bourdieusian tenets are symbolic violence, symbolic suffering, and dominance. These particular concepts availed and functioned as a "thinking map" and a "talking stick" with regard to the study under discussion. A heuristic and ontological landscape was set by the concepts of symbolic violence, dominance and symbolic suffering in building the medico-judicial framework for the rehabilitation of forensic psychiatric patients in Zimbabwe. In other words, the researcher was enabled to have a clearer view of that which was involved in constructing the framework by these concepts. The following is an account of how habitus, field and capital illuminated the study:

\section{Habitus}

Human interaction experiences in the medical system, the judicial system and the prison system underlined the study. In the context of space and time, each system expressed inherent values, normative inclinations and pro-system attitudes. Pierre Bourdieu refers to this as "habitus" (Sullivan, 2002: 149). Habitus in the study was therefore seen as the medical, prison and judicial systems' practices. This conceptualisation in the study availed a platform in analysing and describing the highlighted practices of the systems as they understood them in this study. Bourdieu (cited in Karabel \& Halsey, 1977) further abstracted the habitus concept by writing in 1977: "This means that our object becomes the production of the habitus, that system of dispositions which acts as mediation between structures and practice; more specifically, it becomes necessary to study the laws that determine the tendency of structures to reproduce themselves by producing agents endowed with the system of dispositions which is capable of engendering practices adapted to the structures and thereby contributing to the reproduction of the structures." This abstract explanation by Bourdieu with regard to the habitus is further put into perspective in Calhoun, LiPuma, \& Postone (1993) who positions that "habitus reproduces dominant beliefs, values, and norms through exercise of symbolic power and by bestowing cultural capital". In light of this view, habitus provided a tool used in the analysis of power and domination practices underlying processes of forensic psychiatry rehabilitation.

\section{Field}

Bourdieu highlights human interactions as experiences that cannot happen in isolation or in a vacuum but in a given context which he calls the "social field". A "field" according to Bourdieu is used metaphorically to refer to social space where interactions, relations and positions are understood within such space (Bourdieu, 2005). In view of that position, social fields stand for structures representing divergent social positions where power dynamics will be at play. With regards to the study, the social fields included the prison system, the judi- 
cial system and the medical system. These systems/fields had inherent diverse activity levels which Bourdieu (1984) refers to as "the hierarchy that includes objective relations between the various instances of legitimation." The prison, judicial and the medical systems were viewed and analysed as a field. The focus of analysis was therefore projected on the fields with regard to forensic psychiatric rehabilitation practices within those fields.

Symbolic violence is another of Bourdieu's concept that applied to the study as positioned by Schubert (cited in Grenfell, 2008). Bourdieu correlates symbolic violence to cultural arbitrariness as reflected in the following assertion: "In any given social formation there is a tendency to impose recognition of the legitimacy of the dominant culture on the members of the dominated groups or classes, it tends at the same time to impose on them by inculcation or exclusion, recognition of the illegitimacy of their own cultural arbitrary" (Bourdieu \& Passeron, 1990). This view is further broken down by Thompson (1984) who positions that the tendency by dominant systems to give preferential treatment to particular social classes is an equivalent of symbolic violence. This is to say, for example in this study that, if norms and values of the medical system or the prison system or the judicial system were dominant, they would be considered arbitrary. According to Bourdieu, this arbitrariness would then enforce the values and norms of the dominant group and in the process legitimising these values in the functionality of the systems involved. The legitimisation would then facilitate the reproduction of the interests of the dominant system. This is perceived by Bourdieu as symbolic violence. So for example in this study, forensic psychiatric patients experienced symbolic violence when the dominant prison system operationalized its system and viewed it as legitimate.

The habitus and field are conceptualised by Grenfell (2004) as not only functioning as thinking tools but also as "epistemological matrices lying at the generative root of the action of knowledge formation itself". An example for the study is that it focused in having a grasp of medico-judicial processes that underlined rehabilitation of forensic psychiatric patients in special institutions. Special institutions were psychiatric units located within prison settings in Zimbabwe. The study also sought to understand the realities of medical, judicial, forensic psychiatric patients and family/relatives of forensic psychiatric patients in these processes.

Both habitus and field are seen by Grenfell (2004) as inherent and dispositional. Mangez (2007) put more light to Bourdieu's position by pointing out that the "constructions of a representation of reality also hides other possible ways of understanding and making sense of the world". In view of this assertion, Bourdieu is saying that our world is constructed by the way we understand our environment. In that light Bourdieu is implying that such a world can be reconstructed using different ways of seeing/viewing that world. Developing a medico-judicial framework for rehabilitation of forensic psychiatric patients in the study under discussion therefore represented such form of reality reconstruc- 
tion. The belief of Bourdieu about a socially constructed world is also reflected in the meta-paradigmatic inclination of the researcher for this study.

\section{Capital}

Another central "talking stick" for the study was Bourdieu's concept of capital. The habitus and the field's logic and functional configuration revolve around capital (more cited in Grenfell, 2008). Capital can be economic, social and cultural. The position and trajectory within a field are determined or "bought" by capital (Grenfell, 2004). This means that the prison system's positions or assertion of power as the dominant field was determined by three aspects: the capital they possessed, the capital they imposed on the medical and judicial fields, and that it (the prison system) defined the capital.

It is important to note that Bourdieu proposed that if his concepts were to be used as a theoretical point of departure by a researcher, especially from an epistemological perspective, there would be need for the researcher to utilise three dimensions (Grenfell, 2008). The dimensions are explained as follows: Firstly, the field dimension positions that the research should study the relatedness or dynamics of a particular field to the field that possesses power in view of their functional dynamics. Secondly, the research to which Bourdieu is applied should clearly show structural relational positions inherent in the fields. Thirdly, the dynamics of the habitus of each agent needs to be examined (Bourdieu \& Wacquant, 1992).

In the process of answering the research questions for the study under discussion, it became apparent that the field that had power was the prison system and that it had a dominant position as a field. This emanated from the fact that it housed the special institutions and applied the Zimbabwe Prison Act of 1996 and the Zimbabwe Prison Service Standing Orders (undated) instead of the Zimbabwe Mental Health Act of 1996 in the rehabilitation and care of forensic psychiatric patients. Relational and positional structures evolved during the study process when the habitus of the medical, judiciary and prison systems were analysed. Analysis of findings showed discord and dissonance in the rehabilitation practice of forensic psychiatry.

Bourdieu's concepts were used as a framework decidedly during data analysis. When open/focused and axial codes evolved, emergent themes and categories appeared to be "talking" to concepts of habitus, capital, field and symbolic violence. This means that Pierre Bourdieu was not used in the initial analysis but during the process of interpreting the findings. The decision to use Bourdieu hinged on the fact that the study under discussion sought to have a grasp and comprehension of forensic psychiatry rehabilitation processes in Zimbabwe. In view of that, it is important to note that this behavioural process is a basic inherent nature of the grounded theory approach. This then translates to the notion that Bourdieu's concepts would then apprise the research design and contextualise processes bringing out the reason why findings were the way they were 
(Creswell, 2013; Johnson et al., 2010). Psychiatry as a profession evolved from sociology hence the other reason forusing Pierre Bourdieu as a theoretical point of departure (Creswell, 2007). Data analysis and discussion of findings basically used Bourdieu's concepts to build the participants' actualities and truths.

\section{The Nexus}

Nexus in this article is conceptualised as the point of convergence as related to the philosophy of Pierre Bourdieu and the constructivist grounded theory of Kathy Charmaz. The nexus of Bourdieu and Charmaz is an illustration of how their combination could improve exploration of forensic mental health inequalities. The following shows how Kathy Charmaz's constructivist grounded theory was then linked to Pierre Bourdieu's work:

\section{Qualitative Data Analysis}

Polit \& Beck (2012) draw special attention to qualitative data analysis as involving integration of data, bringing out that which is less visible to be more apparent and manifest, connecting and ascribing outcomes to antecedents. The analysis of the data process aligned to the grounded theory canon and principles of transcription, open coding/focused coding, axial coding and theoretical coding as proposed by Kathy Charmaz.

\section{Transcription}

The research study under discussion had verbatim transcription preceding the data analysis process. Special importance was projected on making it a point that there was accuracy of the transcription process for the interviews conducted. To achieve this, audio-recordings were listened to repeatedly and the support and feedback of peers and the supervisor was also sought (Polit \& Beck, 2012).

Grounded theory was the meta-theoretical basis for the study therefore its analysis was applied to qualitative data. Patterns were derived from data to form categories and thematic codes. The analysed data was from field notes and interview transcripts. The principle of using the constant comparative approach as positioned by the grounded theory data analysis approach was applied (Bowen, 2005; Johnson \& Christensen, 2008; Bowen, 2005). This translated to interactions between the researcher, the data and the evolving framework. Manual coding of data was done for the study instead of the initially proposed ATLAS.tiQDA software. The point was to remain in control of the data and also to own it. This is to say that manual coding enabled the researcher to be sensitive and pick small, minute details or nuances that underlined the processes of rehabilitation of forensic psychiatric patients and the developing framework (Bazeley, 2007; Saldana, 2009).

\section{Open Coding and Focused Coding}

Charmaz (2006) emphasises that constant comparison of data that has been 
coded and new data is preceded and enabled if line by line coding and analysis is done. A grounded theory that embraced constructivism was used for the study being discussed (Charmaz, 2014). The data was linked by subliminal and unobtrusive networks. It was imperative that the researcher should not have lost sight of these networks. The hidden networks and nuanced statements would have been missed if the researcher had used software. It is important to note that in the data for this particular study, these formed the inherent actuality and truths of the data (Charmaz, 2006). In the process of coding data, specific patterns in the data identified a particular phenomenon. The pattern was evolved out of a code label allocated to incidents, situations and objects in the data. In the next stage, the developing codes were analysed to pick evolving recurring themes. Reorganisation and conceptualisation of the themes followed a process in which the themes were assigned a higher order label. The evolving higher order labels were processed until a subcategory which later developed to a major category appeared (Walker \& Myrick, 2006). Major categories were then regrouped to form main themes. The main themes then developed into the central storyline for the medical team, forensic psychiatric patients, and the judiciary and for the relatives of forensic psychiatric patients.

\section{Axial Coding}

Strauss (1987) refers to "a dense texture of relationships around the 'axis' of a category". This statement in the study under discussion translated to abstraction of the main themes and central storylines to develop into codes that formed more complex relationships. In other words, main themes were axially coded for each participant group. The emerging relational characteristics from the data were connected and built around Pierre Bourdieu's concepts that appeared to be "talking" to evolving findings (Bourdieu, 1991: 502). Examples of these are given as follows:

- Discordant engagement of the judicial team or participants to the system of rehabilitation of forensic psychiatric patients,

- Dichotomous reality in which nurses' responsibility is abdicated;

- Prohibitive processes negatively affect overall patient care and recovery for psychiatrists.

These themes rotated around Bourdieu's notion of symbolic power (Bourdieu, 1991). Other examples are themes shown below:

- Patients experience life in the institution as "prisoners" and not as "patients" with ensuing physical, emotional, social and occupational challenges,

- Negative perception of the rehabilitative context by patients relatives.

The themes reflected the position of forensic psychiatric patients and relatives of forensic psychiatric patients. These were constructed around Bourdieu's concepts of objectification, disempowerment, symbolic violence, and symbolic suffering.

Charmaz's grounded theory speaks to specifying conditions during axial cod- 
ing. The above concepts of Bourdieu therefore did just that because they gave a context or conditions impacting, dominating actualities and truths of rehabilitation of forensic psychiatric patients in prison settings (special institutions). Bourdieu's concept of power was also included in the conditions that were rooted and entrenched within a complex network of dominance. Bourdieu's (1989) concepts elucidated and revealed the actions or interactions (Charmaz's other step in axial coding) that formed participants' exposure both outside and inside the prison settings (special institutions). The concepts included objectification of forensic psychiatric patients as well as disempowerment of the relatives of forensic psychiatric patients, nurses, and forensic psychiatric patients themselves. The consequences or outcomes (Charmaz's other step in axial coding) of participants' intercommunication and operations also revolved around Bourdieu's concepts that included symbolic violence that culminated in symbolic suffering of forensic psychiatric patients and their relatives and the voicelessness of nurses within the structures and organisation of the prison system(special institutions).

\section{Theoretical Coding}

Theoretical codes are more complex and show 'possible relationships between categories' (Charmaz, 2006). Theoretical coding subsequently abstracted axial codes to show an integrated connectedness of axial codes and the initial open and focused codes (Charmaz, 2006). Theoretical coding revealed intricate relationships that spun around matters of power. This concept underlined the prison setting (special institution) as a system of dominance. Field notes, researcher's reflections further contextualised relational structures as noted during processes of interaction with data and participants. Pierre Bourdieu's concept of symbolic power was then used to analyse and understand these relationships therefore creating a capacitation to comprehend forensic psychiatry rehabilitation towards developing an enabling medico-judicial framework.

\section{Conclusion}

A Bourdieusian outlook on realities of forensic psychiatric rehabilitation processes in Zimbabwe reinforces the need to reconstruct novel therapeutic jurisprudent strategies for forensic psychiatric patients and gives a voice to health workers in prison settings (special institutions). In the process of this discovery, Charmaz's Grounded Theory availed an open-mindedness that capacitated the researcher to uncover subliminal cues and nuances in data that were central to realities illuminated by Bourdieu. The nexus of Pierre Bourdieu and Kathy Charmaz jointly aided the research process to move through concrete to abstract to complex insights in data.

\section{Implications to Practice}

The process of the study highlights important practice mandates:

- Models of care for forensic psychiatric patients need to be context specific 
and constructed with service users;

- Practitioner in a special institution must be conscious of both his/her own and service user's frame of reference for comprehending the social world;

- Forensic psychiatric practitioner must acknowledge that meaning may change according to context. This prevents making assumptions about service user situations;

- To move away from forensic mental health interventions that are reductionist towards those that embrace emergentism.

\section{Significance of the Article}

The combination of Bourdieu and Charmaz provides insights and understanding of contemporary social groups consistent with interpretive studies dealing with social and organisational contexts. The respective philosophy and method at play are projected to highlight how the discovery of underlying assumptions, contexts and the experiences of those involved in the forensic psychiatric phenomenon evolved.

\section{References}

Bazeley, P. (2007). Qualitative Data Analysis with NVivo. London: Sage.

Bourdieu, P. (1984). The Market of Symbolic Goods. Columbia: Columbia University Press.

Bourdieu, P. (1989). Social Space and Symbolic Power. Sociological Theory, 7, 14-25. https://doi.org/10.2307/202060

Bourdieu, P., \& Passeron, J. (1990). Reproduction in Education, Society and Culture. London: Sage Publications.

Bourdieu, P. (1991). Language and Symbolic Power. Cambridge: Polity.

Bourdieu, P., \& Wacquant, L. J. D. (1992). An Invitation of Reflexive Sociology. Chicago: University of Chicago.

Bourdieu, P. (2005). The Social Structures of the Economy. Cambridge: Polity.

Bowen, G. A. (2005). Preparing a Qualitative Research-Based Dissertation: Lessons Learned. The Qualitative Report, 10, 208-222.

Calhoun, C. J, LiPuma, E., \& Postone, M. (1993). Bourdieu: Critical Perspectives. Cambridge: Polity.

Charmaz, K. (2006). Constructing Grounded Theory: A Practical Guide through Qualitative Analysis. Los Angeles: Sage.

Charmaz, K. (2014). Constructing Grounded Theory. Los Angeles: Sage.

Creswell, J. W. (2007). Qualitative Inquiry and Research Design: Choosing among Five Approaches. Thousand Oaks: Sage.

Creswell, J. W. (2013). Qualitative Inquiry and Research Design: Choosing among Five Approaches. Los Angeles: Sage Publications.

Grenfell, M. J. (2004). Pierre Bourdieu: Agent Provocateur. London: Continuum.

Grenfell, M. J. (2008). Pierre Bourdieu Key Concepts. Stocksfield: Acumen Publishing Limited.

Johnson, B., \& Christensen, L. B. (2008). Educational Research. Quantitative, Qualitative 
and Mixed Approaches. Los Angeles: Sage Publications.

Johnson, B. R., McGowan, M. W., \& Turner, L. A. (2010). Grounded Theory in Practice: Is It Inherently a Mixed Method? Research in the Schools, 1, 65-78.

Karabel, J., \& Halsey, A. H. (1977). Power and Ideology in Education. Oxford: OUP.

Mangez, E. (2007). Complimentary Discussion: Symbolic Structures and Social Structures. Literature Review Part 3. Knowledge and Policy in Education and Health Sectors.

Polit, D. F., \& Beck, C. T. (2012). Nursing Research. Generating and Assessing Evidence for Practice. Philadelphia: Williams \& Wilkins/Wolters Kluwer.

Saldana, J. (2009). The Coding Manual for Qualitative Researchers. Los Angeles: Sage.

Strauss, A. (1987). Qualitative Analysis for Social Scientists. New York, NY: Cambridge University. https://doi.org/10.1017/cbo9780511557842

Sullivan, A. (2002). Bourdieu and Education: How Useful Is Bourdieu's Theory for Researchers? The Netherlands' Journal of Social Sciences, 38, 144-166.

Thompson, J. B. (1984). Studies in the Theory of Ideology. Berkeley, CA: University of California Press.

Walker, D., \& Myrick, F. (2006). Grounded Theory, an Exploration of Process and Procedure. Qualitative Health Research, 16, 547-559.

https://doi.org/10.1177/1049732305285972

Scientific Research Publishing

Submit or recommend next manuscript to SCIRP and we will provide best service for you:

Accepting pre-submission inquiries through Email, Facebook, LinkedIn, Twitter, etc. A wide selection of journals (inclusive of 9 subjects, more than 200 journals)

Providing 24-hour high-quality service

User-friendly online submission system

Fair and swift peer-review system

Efficient typesetting and proofreading procedure

Display of the result of downloads and visits, as well as the number of cited articles

Maximum dissemination of your research work

Submit your manuscript at: http://papersubmission.scirp.org/

Or contact aasoci@scirp.org 